\title{
GCU
}

Glasgow Caledonian

University

University for the Common Good

\section{Evidence of decreased HPV vaccine acceptance in Polish communities within Scotland}

Pollock, K.G.; Tait, B.; Tait, J.; Bielecki, K.; Kirolos, A.; Willocks, L.; Gorman, D.R.

Published in:

Vaccine

DOI:

10.1016/j.vaccine.2018.10.097

Publication date:

2019

Document Version

Author accepted manuscript

Link to publication in ResearchOnline

Citation for published version (Harvard):

Pollock, KG, Tait, B, Tait, J, Bielecki, K, Kirolos, A, Willocks, L \& Gorman, DR 2019, 'Evidence of decreased HPV vaccine acceptance in Polish communities within Scotland', Vaccine, vol. 37, no. 5, pp. 690-692.

https://doi.org/10.1016/j.vaccine.2018.10.097

\section{General rights}

Copyright and moral rights for the publications made accessible in the public portal are retained by the authors and/or other copyright owners and it is a condition of accessing publications that users recognise and abide by the legal requirements associated with these rights.

Take down policy

If you believe that this document breaches copyright please view our takedown policy at https://edshare.gcu.ac.uk/id/eprint/5179 for details of how to contact us. 


\section{Evidence of decreased HPV vaccine acceptance in Polish communities within Scotland}

2 Pollock K.G. ${ }^{1,4^{*}}$, Tait B. ${ }^{3}$, Tait J. ${ }^{3}$, Bielecki K. ${ }^{2}$, Kirolos A. ${ }^{2}$, Willocks L. ${ }^{2}$, Gorman D.R. ${ }^{2}$.

$3 \quad{ }^{1}$ Health Protection Scotland, Meridian Court, Cadogan St, Glasgow, UK

$4 \quad{ }^{2}$ NHS Lothian, Directorate of Public Health and Health Policy, Edinburgh, UK

$5{ }^{3}$ Information Services Division, Gyle Square, Edinburgh, UK

$6{ }^{4}$ School of Health and Life Sciences, Glasgow Caledonian University, Cowcaddens Road, 7 Glasgow, UK

8

$9 \quad{ }^{*}$ Corresponding author: Kevin.pollock@nhs.net

10

11 Keywords: Acceptance; HPV; vaccine; Immunisation; Polish 


\section{Abstract}

14 Human papillomavirus (HPV) vaccines are currently utilised globally in national 15 immunisation programmes. Many new European migrants have settled in the United 16 Kingdom (UK) since the 2004 European Union expansion with approximately 91,000 Polish 17 people resident in Scotland. Following anecdotal reports from several NHS Boards within 18 Scotland of lower HPV vaccine uptake in Polish communities compared with other ethnic 19 minorities, an extract containing both forename and surname, was taken from the Scottish 20 Immunisation Recall System (SIRS) for all girls in S2 and S3 in school years 2014/15 to 21 2016/17. We then used the OnoMap algorithm software to derive ethnicity. OnoMap 22 identified between 289 and 321 age-eligible girls as Polish with significant disparity noted for 23 completed HPV vaccine uptake between UK (87.2-89.8\%) and Polish ethnicities (69.7$2477.2 \%) \quad(\mathrm{P}<0.01)$. Preliminary discussions with Polish families suggest that vaccine 25 programme differences, trust in medical/healthcare practitioners, and cultural influences may 26 be important drivers of acceptance. 
28 In Scotland, since 2008, school-based uptake of both the bivalent and quadrivalent HPV 29 vaccines in girls aged 12-13 has been impressive, with vaccine uptake sustained at levels exceeding $90 \%$ (Sinka et al. 2014). Implementation of the programme began as soon as the school session started in August 2008 following an extensive communication campaign with eye-catching, age-appropriate $\mathrm{TV}$, radio and news coverage over the summer holidays. Nearly all HPV vaccines for this age cohort in Scotland are offered in the school setting.

Despite recent communications to head teachers and school nurses from anti-HPV vaccine groups in the UK, those involved in the programme remain committed to ensuring high uptake of the vaccine continues. Although the vaccine programme has been successful within the UK, the Republic of Ireland has observed considerable disparities in school uptake associated with socioeconomic disadvantage (Migone et al., 2017). Furthermore, while parental intent and knowledge of the HPV vaccines has increased over time, lack of perceived importance of HPV vaccination and parental concerns about vaccine safety remain barriers to both HPV vaccination series initiation and completion, especially in the USA

42 (Hanson et al. 2018).

Many new European migrants have settled in the United Kingdom since the 2004 European

44 Union expansion with approximately 91,000 Polish people now resident in Scotland (National Records of Scotland, 2017). Following anecdotal reports from several of Scotland's 14 regional NHS Boards of lower HPV vaccine uptake in Polish communities, we aimed to

47 formally assess uptake of HPV vaccine in Polish girls through ethnicity analysis at the 48 national level. 
50 An extract, containing both forename and surname, was taken from SIRS, for all girls in S3 51 in the school years $2014 / 15$ to $2016 / 17$. S3 is the third year of secondary school in Scotland (year 10 in England) and girls are aged 13-14. These extracts were then fed through OnoMap Name Classification software to derive ethnicity (Onomap; Publicprofiler Ltd, UK). Onomap offers an effective methodology for identifying population groups in both health-related and educational datasets, categorizing populations into a variety of ethnic groups. Previous evaluations have suggested that it can successfully assist health researchers, planners and policy makers in identifying and addressing health inequalities (Lakha et al. 2011). The surname and forename recorded in the SIRS database for each person were matched to an Onomap subgroup, which is the lowest level in the Onomap classification system. Furthermore, as a sense check, one of the Polish speaking authors assessed forename/surname composition in the SIRS extract, confirming that Onomap was an appropriate tool for estimation of ethnicity. Ethnicity was categorised into UK, Eastern European, and Polish.

The cohort data was based on girls registered in S3 in Scotland on Child Health Schools Programme-School (CHSP-S) as at mid-May of the relevant school year. The vaccination data by ethnicity was based on the SIRS extract as at mid-August following the end of each school year. The published Scotland totals refer to uptake rates reported for the S3 cohort at the time the data for each school year were first published as national statistics. A completed course of HPV in 2014/15 was three doses of HPV, while in 2015/16 and 2016/17 it was two doses (Chief Medical Officer for Scotland, 2014). Ethical approval was obtained from the Public Health Intelligence Information Governance committee and approved by the relevant Caldicott Guardian. 


\section{Results}

73 The majority of girls in S3 in each of the three annual cohorts were classed as British Isles, 74 ranging from $90.2 \%$ to $91.8 \%$. The percentage of S3 girls who were identified as Eastern

75 Europe ranged from $1.4 \%$ to $1.6 \%$. Approximately $75 \%$ of those identified as Eastern 76 European were identified as Polish (Table 1).

77 Uptake in Eastern European and Polish S3 girls (range 68.1-75.5\%; 69.7-79.2\%) was 78 significantly lower than in girls categorised as UK $(87.2-89.6 \%)(\mathrm{P}<0.01)$. The trend in 79 uptake across the three years was similar for the three different, with uptake falling in $802015 / 16$ then increasing in 2016/17. The decrease in uptake in 2015/16 was larger among 81 girls classed as Eastern European and the Polish sub-group, compared with UK girls. 82 Although uptake rates rebounded in 2016/17 among all three groups, it was only the uptake among UK girls that recovered to the level observed in 2014/15 (Table 1). 
85 Table 1. Uptake of completed course of HPV by S3 by Ethnic Groups and Academic

86 Year.

\begin{tabular}{|c|c|c|c|c|c|}
\hline \multirow{2}{*}{$\begin{array}{l}\text { School } \\
\text { Year }\end{array}$} & \multirow[b]{2}{*}{ Ethnicity } & \multirow[b]{2}{*}{ S3 Cohort } & \multicolumn{2}{|c|}{ Completed HPV } & \multirow[b]{2}{*}{$95 \% \mathrm{Cl}$} \\
\hline & & & $n$ & $\%$ & \\
\hline \multirow{4}{*}{$2014 / 15$} & UK & 24,377 & 21,840 & 89.6 & $(89.2-90.0)$ \\
\hline & Eastern Europe & 376 & 284 & 75.5 & (70.9-79.6) \\
\hline & Polish & 289 & 223 & 77.2 & $(72.0-81.6)$ \\
\hline & $\begin{array}{l}\text { Published Scotland } \\
\text { Total }\end{array}$ & 26,554 & 23,588 & 88.8 & \\
\hline \multirow{4}{*}{ 2015/16 } & UK & 23,816 & 20,775 & 87.2 & $(86.8-87.6)$ \\
\hline & Eastern Europe & 382 & 260 & 68.1 & $(63.2-72.5)$ \\
\hline & Polish & 300 & 209 & 69.7 & (64.2-74.6) \\
\hline & $\begin{array}{l}\text { Published Scotland } \\
\text { Total }\end{array}$ & 26,104 & 22,570 & 86.5 & \\
\hline \multirow{4}{*}{ 2016/17 } & UK & 23,389 & 20,998 & 89.8 & $(89.4-90.2)$ \\
\hline & Eastern Europe & 418 & 304 & 72.7 & (68.3-76.8) \\
\hline & Polish & 321 & 231 & 72.0 & (66.8-76.6) \\
\hline & $\begin{array}{l}\text { Published Scotland } \\
\text { Total }\end{array}$ & 25,932 & 23,040 & 88.8 & \\
\hline
\end{tabular}

87 
90 In this study, we confirmed a significant disparity in HPV vaccine uptake amongst Eastern

91 European and Polish communities within Scotland, a country with high uptake since programme inception. This phenomenon appears to be uniquely associated with Polish and Eastern European communities, since uptake of the HPV vaccine in girls from the Indian subcontinent was comparable ( $86 \%$ for two doses) to those identified as being UK born. Within the EU, Poland is one of eight countries where HPV vaccination is yet to have been made part of a free-of-charge mandatory form of immunisation programme (Ganczak et al. 2018). Consequently, HPV vaccination coverage in adolescent Polish girls is estimated at $1.5-10 \%$. This is much lower than those reported in countries where the cost of vaccinations is covered from the national budget. Poland has recognised issues with vaccine hesitancy and an active anti-vaccination movement (Braczkowska et al., 2017; Jaroszewska et al., 2014).

However, notwithstanding that, the recent study by Ganczak and colleagues demonstrated that attitudes regarding their child being vaccinated against HPV were generally positive among Polish parents, even though awareness and knowledge of HPV in this group were low.

If a girl wants vaccination the vaccine must be purchased by the parents and administered through primary health care or outpatient clinic. Most of the significant factors that influenced their willingness were modifiable, such as being informed about HPV and having positive attitudes toward vaccines.

These findings have important implications for the trans-national study of vaccine uptake and the drivers of these, especially in countries that experience significant immigration. The main aim of characterizing the nature and scale of vaccine acceptance issues is to appropriately inform the development of strategies and policies to address the concerns expressed, while sustaining confidence in vaccination (Larson et al. 2015). Reducing inequalities is also a key 
aim of generating and maintaining equitable uptake of vaccines, and where cervical cancer disproportionately affects the most deprived, it is even more important to ensure uptake of the HPV vaccine is evenly distributed across national populations.

One of the main limitations of our study was the reliance on the Onomap naming algorithm to accurately identify ethnicity. The utility of Onomap has been validated in several studies (Smith et al. 2017). Combining ethnicity from multiple sources results in a more complete estimate of ethnicity than the use of one single source but we believe that this does not significantly affect the main findings of this study. The phenomenon of decreased vaccine uptake is prevalent in the Polish communities within Scotland, as is demonstrated in another study that was performed simultaneously for childhood influenza vaccine (Bielecki et al. 2018 - manuscript submitted to Vaccine). This study only involved administrative uptake data and not parent interviews. Consequently, this study was unable to discern the actual reasons behind the lower HPV uptake among Polish girls and was not able to identify whether, and to what extent, parents were reluctant or concerned about HPV vaccination.

Despite higher rates of HPV vaccine uptake compared to those residents in Poland, this study demonstrates significantly lower rates of HPV vaccine uptake in girls of Polish and Eastern European ethnicity compared to others in Scotland. We have conducted an explorative qualitative study with Polish families, which suggest that vaccine programme differences between Poland and the UK, trust in medical/healthcare practitioners, and cultural influences may be important drivers of acceptance. Furthermore, this qualitative study has revealed that Polish women expressed fears in relation to the side-effects of the HPV vaccine, an independent predictor of parental willingness to have their child vaccinated (Ganczak et al. 2018). Strategies to promote uptake of HPV vaccines amongst Polish and Eastern European communities should be promoted, especially given poor uptake of cervical screening in these 


\section{References}

139 Braczkowska B, Kowalska M, Braczkowski R, Barański K. Determinants of vaccine 140 hesitancy. Przegl Epidemiol. 2017;71(2): 227-236.

Chief

Medical

Officer

for

Scotland

(2014).

142 http://www.sehd.scot.nhs.uk/cmo/CMO(2014)20.pdf [accessed 5th 135 July 18]

143

144

Ganczak M, Owsianka B, Korzeń M. Factors that Predict Parental Willingness to Have Their Children Vaccinated against HPV in a Country with Low HPV Vaccination Coverage. Int J Environ Res Public Health. 2018 Mar 31;15(4). pii: E645.

Hanson KE, Koch B, Bonner K, McRee AL, Basta NE. National Trends in Parental HPV Vaccination Intentions and Reasons for Hesitancy, 2010-2015. Clin Infect Dis. 2018 Mar 27. doi: $10.1093 /$ cid/ciy232.

Jaroszewska K, Marciniak A, Gawlak M, Życińska K, Wardyn K, Nitsch-Osuch A.

Perception of anti-vaccination movements by parents of young children. Postępy Nauk

Medycznych. 2014; 9: 617-621.

Lakha F, Gorman DR, Mateos P. Name analysis to classify populations by ethnicity in public health: validation of Onomap in Scotland. Public Health. 2011; 125: 688-696.

Larson HJ, Jarrett C, Schulz WS, Chaudhuri M, Zhou Y, Dube E, Schuster M, MacDonald NE, Wilson R; SAGE Working Group on Vaccine Hesitancy. Measuring vaccine hesitancy: The development of a survey tool. Vaccine. 2015;33: 4165-75.

Maździarz A, Wyględowski J, Osuch B, Jagielska B, Śpiewankiewicz B. New directions in cervical cancer prophylaxis worldwide and in Poland - Case study of the Polish rural female 
population. Ann Agric Environ Med. 2017; 24: 592-595.

160 Migone C, Barrett T, Cotter S, Clarke A, Corcoran B. The Uptake of Human Papillomavirus 161 Vaccine In Irish Schools: The Impact Of Disadvantage. Ir Med J 2017; 110(7):603.

\section{National} Records

of

Scotland

163 https://www.nrscotland.gov.uk/files/statistics/population-estimates/pop-cob-16/pop-count-

164 birth.pdf [accessed 5th July 2018]

165 Potts A, Sinka K, Love J et al. High uptake of HPV immunisation in Scotland - perspectives 166 on maximising uptake. Eurosurveillance 2013; 18:20593.

167 Sinka K, Kavanagh K, Gordon R et al. Achieving high and equitable coverage of adolescent 168 HPV vaccine in Scotland. J Epidemiol Community Health 2014; 68:57-63.

169 Smith L, Norman P, Kapetanstrataki M, et al. Comparison of ethnic group classification 170 using naming analysis and routinely collected data: application to cancer incidence trends in 171 children and young people. BMJ Open 2017;7:e016332. 